\title{
Facilitators and barriers to participation of the private sector health facilities in health insurance \& government-led schemes in India
}

\author{
Harsh S. Dave, Jay R. Patwa *,1, Niraj B. Pandit \\ Community Medicine Department, SBKS MIRC, Sumandeep Vidyapeeth, Waghodia, Vadodara, Gujarat, India
}

\section{A R T I C L E I N F O}

\section{Keywords:}

Ayushman bharat

Out of pocket expenditure

Public-funded health insurance

Service providers' perception

Universal health coverage (UHC)

\begin{abstract}
A B S T R A C T
Background: In India, policymakers are in an opined that expansion of public-funded health insurance is the key to achieve Universal Health Coverage (UHC). Despite untapped potential to be part of such government-run public-funded health scheme, many private service providers are reluctant to join in such scheme due to various reasons. This paper aims to evaluate facilitators, barriers and perception to participation of the private sector health facilities in Health Insurance \& government-led schemes.

Methods: Present study was conducted in 83 private hospitals of Vadodara city. Sampling frame was formed \& with the use of random number table, 83 hospitals were selected randomly. Data collection was done in pre tested, pre formed questionnaire \& respondents were the medical superintendent or the person in-charge of the hospital.

Results: In the present study $30 \% \& 26 \%$ of hospitals were enrolled for cashless private health insurance facility \& government health schemes respectively. Social service, competition and increase clientele were the common reason sought for enrolment in government health schemes. Low \& delayed reimbursement, bribe to clear payment, limited services covered, administrative issues were the common problems identified for nonenrolment. There was an association between a number of beds in the hospital \& enrolment to government health scheme $(\mathrm{p}<0.05)$. Availability of cashless private health insurance facility $(\mathrm{p}<0.01)$ and satisfied with the current TPA model of health insurance $(\mathrm{p}<0.05)$ were also found statistically significant.

Conclusion: Timely \& rational increase in remuneration, expanding the scope of services and use of appropriate technology for ease in administration is the need of an hour to engage vast service providers under the ambit of public-funded health insurance.
\end{abstract}

\section{Introduction}

Accomplishing Universal Health Coverage (UHC) gained global push to inculcate in nation's health policy which is a reflection of world health assembly resolution (2005), World Health Theme 2018 and Sustainable Development Goal (SDG) objective 3.8. ${ }^{1,2}$ The ultimate goal of UHC is to ensure that everyone should have access to essential healthcare services everywhere, without bearing financial hardship. ${ }^{3}$ Nation like India with miserable national health spending requires an effective \& efficient health financing tool to implement UHC. ${ }^{4}$ Health insurance is one such model that works on pooling risk and resources which gives premium \& business to the insurer, more clientele to service provider \& quality services without out of pocket expenditure to an insured.

In India, policymakers are in an opined that expansion of publicfunded health insurance is the key to achieve UHC. ${ }^{5-7}$ In the last two decades, state and central governments in India funded several Health insurance schemes to circumvent impoverished people from catastrophic health expenditure. ${ }^{8-10}$ National Rural Health Mission (NRHM) was launched in 2005 to narrow down systemic deficiencies in the Indian health system. ${ }^{11}$ While health sector reforms brought by NRHM was focused towards strengthening public health system, subsequently launched public-funded health insurance schemes (E.g. Rashtriya Swashtya Bima Yojana (RSBY) \& Ayushman Bharat at national level,

\footnotetext{
* Corresponding author. Community Medicine Department, Dr. N. D. Desai Faculty of Medical Science \& Research, 58/2 Meghdoot Society, Nadiad - 387001, Gujarat. India.

E-mail addresses: harshsdave@gmail.com (H.S. Dave), drjpatwa@gmail.com (J.R. Patwa), drniraj74@gmail.com (N.B. Pandit).

${ }^{1}$ Present Address - Assistant Professor, Community Medicine Department, Dr. N. D. Desai Faculty of Medical Science \& Research, Dharmsinh Desai University, College road, Nadiad, Gujarat, India. Pin Code: 387001.
} 
Mukhyamantri Amrutam Yojana (MAA Yojana) \& Chiranjeevi Yojana in Gujarat Etc.) gave level playing field to private service providers. ${ }^{9,12-14}$ India has one of the most privatized medical systems on the planet where the private sector serving $80 \%$ of outpatient care and up to $60 \%$ of inpatient care in the nation. ${ }^{15,16}$ As the private sector is holding lion's share in India, any model which aims to achieve Universal Health Coverage (UHC) can't ignore private sector despite the concern of transparency, ethics, cost and quality of care. ${ }^{17,18}$ All of these schemes empowering the beneficiary by providing cashless services $\&$ freedom to choose between public and private hospitals. Despite this huge opportunity, many private service providers are reluctant to join in such government-run public-funded health schemes due to various reasons. $^{19-21}$

Till time, research has been centred around awareness, utilization and coverage evaluation of public-funded insurance scheme. Very little attention has been given to understand the service providers' enrolment rate \& perspective for such schemes. The private sector has its own perception \& challenges regarding health insurance and governmentrun health schemes. In a currently challenging time of a fraudulent claim, moral hazard and rising premium in the health insurance sector, it is a tough task for policymakers to form a balanced policy which can provide affordable healthcare with keeping the viability of insurance sector intact \& lucrative enough for private providers to enrol for it. This paper aims to evaluate facilitators, barriers and perception to participation of the private sector health facilities in Health Insurance \& government-led schemes.

A cross-sectional study was conducted on the private hospitals of Vadodara city. Private hospitals and nursing homes with less than 15 indoor bed capacity, ${ }^{22}$ Government hospitals and hospitals not willing to participate in the study were excluded. Total of 575 hospitals were registered with the health department of Vadodara Municipal Corporation as a health establishment. More than 15 indoor beds hospital were considered for the study, a total of 391 hospitals were eligible for the study. The sampling frame was formed by assigning a unique serial number to all eligible hospitals. Based on these data, the sample size was calculated using a standard formula. ${ }^{23}$ A sample size of 79 was derived by taking 391 as a population, $48 \%$ as a proportion (Derived from the pilot study), $95 \%$ confidence level with a $10 \%$ margin of error. Considering $5 \%$ non-response rate, the final sample size of 83 was achieved. By using a random number table, 83 Random numbers were generated from the unique serial number sampling frame \& corresponding list of 83 hospitals were nominated for the study (Image: 1). After obtaining permission from the Institutional ethical committee, data collection was done in August \& September 2018 in a pre-tested, preformed questionnaire. A prior personal appointment was taken for interview \& after taking informed consent, data were collected in the questionnaire form from the medical superintendent or the person-in-charge of the hospital. Questionnaire on Government health schemes includes Rashtriya Swathya BimaYojana (RSBY), Janani Suraksha Yojana (JSY), state-sponsored Chiranjeevi Yojana, Mukhya Mantri Amrutam Yojana ( MAA Yojana) \& any other government-sponsored health assistance schemes.

Statistical Analysis: Collected data were compiled in Microsoft office Excel 2010 format. Data were processed using Epi info statistical software version 7.2. Frequency, proportions were obtained from the collected data and cross tables were formed with the number of hospital beds for comparison. Chi-square test was applied to check for the association. P-value $<0.05$ was taken as statistically significant.

\section{Results}

Present study was conducted to understand the perception of private health facility towards health Insurance (Fig. 1). In the present study out of 83 hospitals, $89 \%$ hospitals were small scale hospitals (less than 50 indoor bed) while around $11 \%$ hospitals were mid to large scale hospitals ( 50 or more indoor bed). Around $29 \%$ of hospitals were providing multispecialty services followed by medicine (21\%), orthopaedics, gynaecology and paediatrics (15\% each) \& others like surgery, ENT etc.. Hospital authorities revealed that daily average OPD, Indoor occupancy rate \& proportion of patients having health insurance were $26.9,22.15 \%$ \& 40\% respectively (Table 1 ).

For the small scale hospital, social service was the most common reason to opt for government health schemes while large scale hospitals opted for it mainly due to competition \& to increase clientele. All service providers with more than 100 bedded hospitals \& $25 \%$ of $50-100$ bedded hospital had enrolled for government health schemes. Low reimbursement was the prime reason for the non-enrolment. Apart from it, administrative problems with a heavy patient load and delayed reimbursement were the major reasons for non-enrolment.

Unawareness about detail terms \& condition of health insurance, an unnecessary argument for higher deduction or longer time taken by TPA to pass the claim were major challenges faced by all hospitals from clients. Apart from these, request to inflate bills, request for unnecessary hospitalization and diagnostic tests etc. moral hazards \& fraudulent activity and demanding patients and relatives for hospitality facility were common in both small \& mid to large scale hospitals. The limited scope of services offered \& lots of administrative work were major problems for all hospitals while delayed payment and bribe for clearance of payment were major challenges faced by mainly small hospitals while dealing with government health schemes (Table 2).

A large number of small scale hospitals were not willing to enrol for both Government \& private cashless health insurance schemes compare to mid to large scale hospitals. Association was found between the number of beds in the hospital \& enrolment to government health scheme, availability of cashless private health insurance facility and satisfied with the current TPA model of health insurance. This difference was found statistically significant. (Yates corrected $\mathrm{p}$ value $<0.05$ ) (Table 3). 


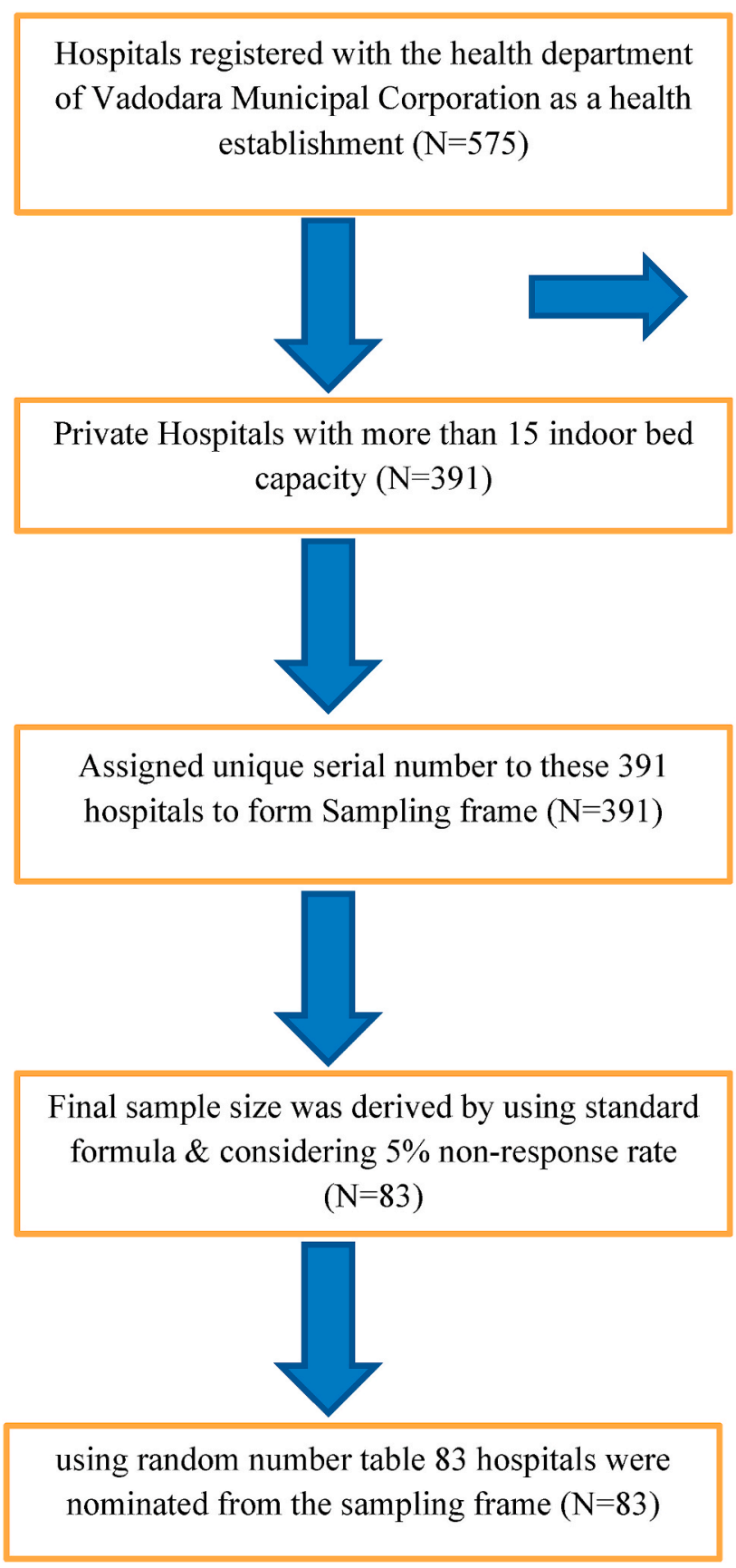

\section{Discussion}

The present study was carried out in 83 hospitals of Vadodara city to understand service providers' perception regarding health insurance. In the present study, the majority of the hospitals were of small scale with less than 50 beds while very few were mid to large scale hospitals. In the present study out of all eligible hospitals, only $30 \%$ of hospitals were offering cashless private health insurance facility while only $26 \%$ of hospitals were offering government health schemes. This suggests that urban cities still have huge scope for improvement in enrolment for cashless schemes either from private or government schemes. Any comparable study mentioning hospital enrolment rate either for cashless private or for government health schemes was not found. As per the agreement, Government or Third-party administrator (TPA) has to pay the claim settlement amount to the hospital within 21 days of discharge of patient. However, in the present study, none of the service providers received the claim settlement amount within 21 days \& the majority of them received it within 21-30 days which shows there is a lapse in the system. Similar findings were observed by Kumar et al., Trivedi et al. and Rajib Dasgupta et al.. ${ }^{13,21,24}$

Social service was the most common motive for small scale hospitals to opt for government health schemes while mid to large scale hospitals had opted it as a part of business strategy to attract more clients, increase occupancy rate \& survive in the competition. Present study findings were similar to the qualitative study done by Yadav et al. on Janani SurakshaYojana (JSY) \& Ganguly et al. on Chiranjeevi Yojana. ${ }^{19,20}$ Administrative problem, heavy patient load, low and delayed reimbursement were the common reasons sought for non-enrolment to government health schemes. However, having a heavy patient load is contradictory to the average daily OPD \& bed occupancy rate. This 


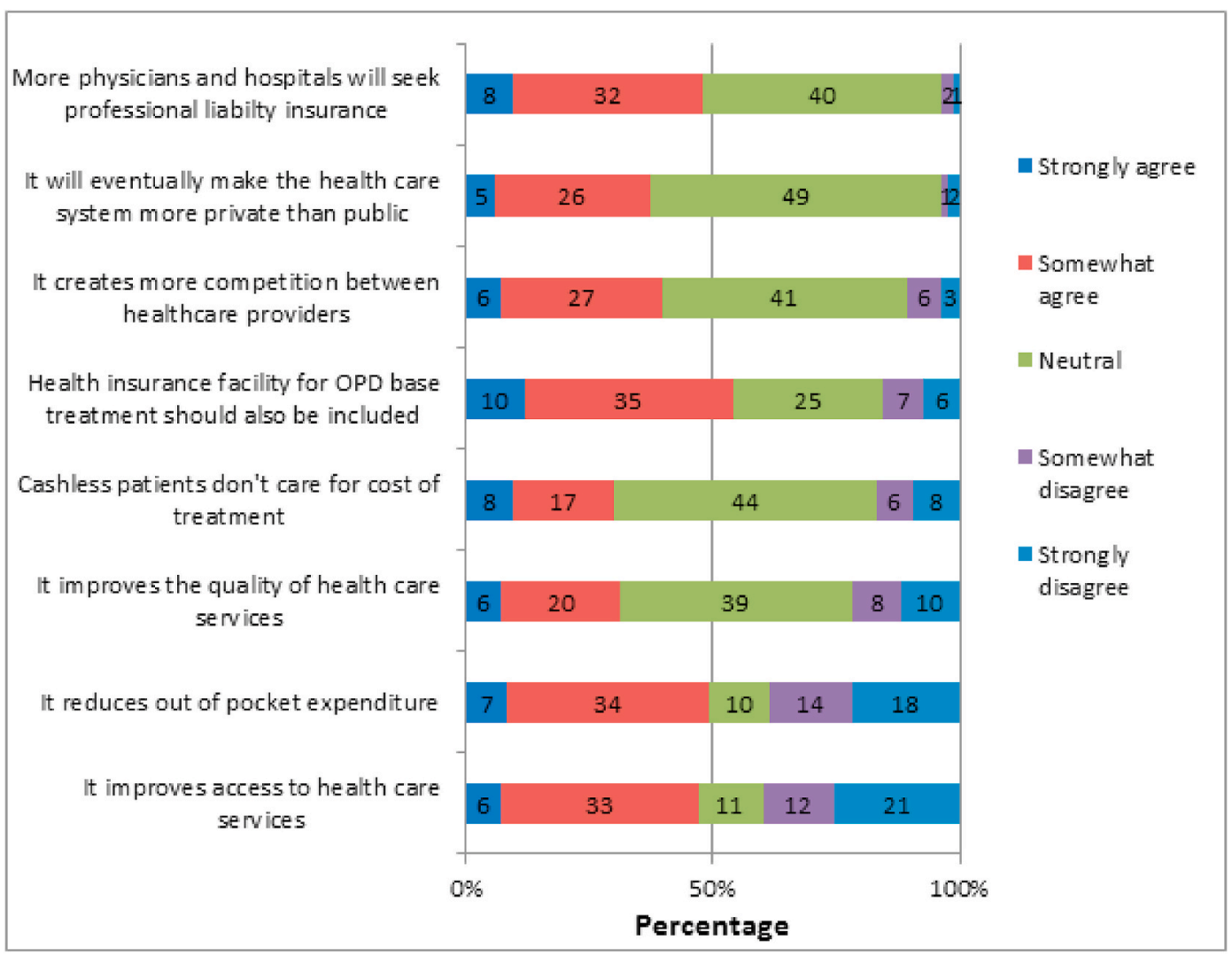

Fig. 1. Perception of health care service provider on health insurance.

Table 1

Hospital statistics \& its attribute for health insurance.

\begin{tabular}{|c|c|c|c|}
\hline Variable & \multicolumn{2}{|c|}{ Characteristic } & $\begin{array}{l}\text { Frequency } \\
(\%)\end{array}$ \\
\hline \multirow[t]{3}{*}{ Number of beds in the hospital } & \multicolumn{2}{|l|}{$<50$} & $74(89.15 \%)$ \\
\hline & \multicolumn{2}{|l|}{$\geq 50$} & $9(10.85 \%)$ \\
\hline & \multicolumn{2}{|c|}{ Total } & $83(100 \%)$ \\
\hline \multirow[t]{4}{*}{$\begin{array}{l}\text { Health insurance facility } \\
\text { available at hospital }\end{array}$} & \multirow[t]{3}{*}{ Yes } & $\begin{array}{l}\text { Cashless private } \\
\text { insurance available }\end{array}$ & $25(30.12 \%)$ \\
\hline & & $\begin{array}{l}\text { Government health } \\
\text { scheme available }\end{array}$ & $22(26.50 \%)$ \\
\hline & & $\begin{array}{l}\text { Total (Any scheme } \\
\text { available) }\end{array}$ & $25(30.12 \%)$ \\
\hline & \multicolumn{2}{|l|}{ No } & $58(69.88 \%)$ \\
\hline \multirow{2}{*}{$\begin{array}{l}\text { Hospitals Satisfied with current } \\
\text { TPA model for health insurance }\end{array}$} & \multicolumn{2}{|l|}{ Yes } & $12(14.46 \%)$ \\
\hline & \multicolumn{2}{|l|}{ No } & $71(85.54 \%)$ \\
\hline \multirow{2}{*}{$\begin{array}{l}\text { In cashless cases, cost of } \\
\text { treatment is high at hospital ( } \mathrm{n} \\
=25 \text { ) }\end{array}$} & \multicolumn{2}{|l|}{ Yes } & $7(28 \%)$ \\
\hline & \multicolumn{2}{|l|}{ No } & $18(72 \%)$ \\
\hline \multirow{3}{*}{$\begin{array}{l}\text { Time taken to receive money } \\
\text { from insurance }\end{array}$} & \multicolumn{2}{|c|}{$<21$ days (as per norm) } & 0 \\
\hline & \multicolumn{2}{|c|}{$21-30$ days } & $22(88 \%)$ \\
\hline & \multicolumn{2}{|c|}{ 1-3 months } & $3(12 \%)$ \\
\hline
\end{tabular}

might be because of under-reporting of OPD \& IPD data or due to skewed distribution.

Administrative issues, limited services covered, delayed reimbursement and bribe for clearance of payment were the biggest challenges faced by all hospitals while dealing with government health schemes. Similar findings were observed by Yadav et al. \& Rajib Dasgupta et al. in which study was done on maternal government health schemes \& on RSBY respectively. ${ }^{19,21}$ It is noted that despite strict measures to curb fraudulent activity; request for unnecessary hospitalization, diagnosis and inflate bills were reported by all type of hospitals. Poor awareness about terms \& condition of policy and more expectation from the
Table 2

Challenges faced by hospitals from client side and while dealing with government health schemes (Multiple answers allowed).

\begin{tabular}{lll}
\hline Characteristic & \multicolumn{2}{l}{$\begin{array}{l}\text { Number of response } \\
\text { (Percentage) }\end{array}$} \\
\cline { 2 - 3 } & $<50$ beds & $\geq 50$ beds \\
\hline Challenges faced by hospitals from client side due to & health insurance $(\mathrm{n}=83)$ \\
Not aware about Terms \& conditions of policy & $50(45.05 \%)$ & $9(42.86 \%)$ \\
Unnecessary argument for higher deduction or & $32(28.83 \%)$ & $6(28.57 \%)$ \\
longer time taken by TPA to pass claim & & \\
Request to involve in moral hazards \& fraudulent & $11(9.90 \%)$ & $4(19.05 \%)$ \\
activity & & \\
More Demanding & $18(16.22 \%)$ & $2(9.52 \%)$ \\
Total & 111 & 21 \\
& $(100.00 \%)$ & $(100.00 \%)$ \\
Problems faced by hospitals while dealing with government health schemes $(\mathrm{n}=22)$ \\
Limited services covered & $11(32.35 \%)$ & $6(46.15 \%)$ \\
Lots of paper work & $8(23.52 \%)$ & $5(38.46 \%)$ \\
Bribe for clearance of payment & $9(26.47 \%)$ & $2(15.38 \%)$ \\
Delayed reimbursement & $5(14.70 \%)$ & 0 \\
Other & $1(2.94 \%)$ & 0 \\
Total & 34 & 13 \\
& $(100.00 \%)$ & $(100.00 \%)$ \\
\hline
\end{tabular}

hospital were the other common challenges faced by the private hospital from client-side due to health insurance. Similar findings were reported by Kumar et al. \& Ganguly et al.. ${ }^{20,24}$

The present study indicates that mid \& large hospitals are ready to enrol for any scheme or model that increases client \& revenue for them. For small hospitals, additional manpower requirement for the administration of health insurance $\&$ reimbursement related issue is adversely affecting their working capital cycle. Also due to limited infrastructure \& human resources, they can't manage excess patient load which is expected if they enrol for any scheme. So small scale hospitals were 
Table 3

Association between numbers of beds in the hospital with enrolment to health insurance schemes.

\begin{tabular}{|c|c|c|c|c|}
\hline \multirow[t]{2}{*}{ Variable } & \multirow[t]{2}{*}{ Response } & \multicolumn{2}{|c|}{ Hospitals } & \multirow{2}{*}{$\begin{array}{l}\text { Yates' chi-square } \\
\text { value ( } \mathrm{p} \text { - value) }\end{array}$} \\
\hline & & $\begin{array}{l}<50 \\
\text { beds }\end{array}$ & $\begin{array}{l}\geq 50 \\
\text { beds }\end{array}$ & \\
\hline \multirow{2}{*}{$\begin{array}{l}\text { Enrol to Government health } \\
\text { scheme }\end{array}$} & Yes & 16 & 6 & \multirow[t]{2}{*}{$6.205(\mathrm{p}<0.05)$} \\
\hline & No & 58 & 3 & \\
\hline \multirow{2}{*}{$\begin{array}{l}\text { Availability of Cashless } \\
\text { private health insurance } \\
\text { facility }\end{array}$} & Yes & 17 & 8 & \multirow[t]{2}{*}{$13.58(\mathrm{p}<0.01)$} \\
\hline & No & 57 & 1 & \\
\hline \multirow{2}{*}{$\begin{array}{l}\text { Satisfied with current TPA } \\
\text { model of health insurance }\end{array}$} & Yes & 16 & 6 & \multirow[t]{2}{*}{$6.205(\mathrm{p}<0.05)$} \\
\hline & No & 58 & 3 & \\
\hline
\end{tabular}

hesitant to join for private or government health insurance scheme. In the present study, an association was found between a number of beds in the hospital \& enrolment to government health scheme, availability of cashless private health insurance facility and satisfied with current TPA model of health insurance $\&$ this difference was found statistically significant.

\section{Conclusion}

From the present study we conclude that apart from providing social service to the needy people, hospitals are enrolling with health insurance schemes to increase clientele \& revenue. However meagre enrolment of the service provider with insurance scheme is because of several tailbacks like Low \& delayed reimbursement, limited services covered and administrative issues. Poor awareness about policy terms, request to involve in moral hazard \& fraudulent activity and demanding patients are other challenges from the client-side. Timely \& rational increase in remuneration, expanding the scope of services and use of appropriate technology for ease in administration is the need of an hour to engage vast service providers under the ambit of health insurance.

\section{Financial support}

This research project was selected for ICMR STS (Indian Council of Medical Research - Short Term Studentship), India \& authors have received the stipend for the same (Reference No. - 201802615). However funding agency has no influence in study design; in the collection, analysis and interpretation of data; in the writing of the report; and in the decision to submit the article for publication.

\section{Declaration of competing interest}

Nil.

\section{Acknowledgement}

The authors would like to acknowledge ICMR STS (Indian Council of Medical Research - Short Term Studentship).

\section{References}

1 Who. Campaign essentials for world health day [Internet]. [cited 2020 Sep 7]. Available from: https://www.who.int/campaigns/world-health-day/2018/campai gn-essentials/en/; 2018.

2 Tangcharoensathien V, Mills A, Palu T. Accelerating health equity: the key role of universal health coverage in the Sustainable Development Goals. BMC Med. 2015;13 (1). Dec [cited 2020 Sep 9] http://bmcmedicine.biomedcentral.com/articles/10.118 6/s12916-015-0342-3.

3 Zodpey S, Farooqui H. Universal health coverage in India: progress achieved \& the way forward. Indian J Med Res. 2018;147(4):327.

4 Prinja S, Kaur M, Kumar R. Universal health insurance in India: ensuring equity, efficiency, and quality. Indian J Community Med. 2012;37(3):142.

5 Sarwal R. Reforming central government health scheme into a 'universal health coverage' model. Natl Med J India. 2015;28(1):9.

6 Kumar AKS, Chen LC, Choudhury M, et al. Financing health care for all: challenges and opportunities. Lancet Lond Engl. 2011;377(9766):668-679. Feb 19.

7 Dror DM, Vellakkal S. Is RSBY India's platform to implementing universal hospital insurance? Indian J Med Res. 2012;135:56-63.

8 Dash A, Mohanty SK. Do poor people in the poorer states pay more for healthcare in India? BMC Publ Health. 2019;19(1). Dec [cited 2020 Sep 17] https://bmcpublicheal th.biomedcentral.com/articles/10.1186/s12889-019-7342-8.

9 Lahariya C. 'Ayushman Bharat' program and universal health coverage in India. Indian Pediatr. 2018;55(6):495-506. Jun.

10 Karan A, Yip W, Mahal A. Extending health insurance to the poor in India: an impact evaluation of Rashtriya Swasthya Bima Yojana on out of pocket spending for healthcare. Soc Sci Med. 2017 May;181:83-92.

11 Nandan D. National rural health mission: turning into reality. Indian J Community Med. 2010;35(4):453.

12 Vellakkal S, Gupta A, Khan Z, et al. Has India's national rural health mission reduced inequities in maternal health services? A pre-post repeated cross-sectional study. Health Pol Plann. 2017;32(1):79-90. Feb.

13 Trivedi M, Saxena DB. Third angle of RSBY: service providers' perspective to RSBYoperational issues in Gujarat. J Fam Med Prim Care. 2013;2(2):169-172. Apr.

14 Shirisha P. What lessons should pradhan mantri jan arogya yojana learn from the shortfalls of rashtriya swasthya bima yojana: the case of rashtriya swasthya bima yojana in Chhattisgarh. Indian J Community Med. 2020;45(2):135.

15 Rao M, Rao KD, Kumar AKS, Chatterjee M, Sundararaman T. Human resources for health in India. Lancet Lond Engl. 2011;377(9765):587-598. Feb 12.

16 Bhatia JC, Cleland J. Health-care seeking and expenditure by young Indian mothers in the public and private sectors. Health Pol Plann. 2001;16(1):55-61. Mar.

17 Duggal R. Private health insurance and access to healthcare. Indian J Med Ethics; 2011 [cited 2020 Sep 18]; Available from: http://ijme.in/articles/private-health-in surance-and-access-to-healthcare/?galley $=\mathrm{html}$.

18 Saxena N, Singh P, Mishra A. A qualitative comparative analysis of healthcare Supply-Demand side barriers under the publicly funded health insurance scheme in India. Indian J Publ Health. 2019;63(4):318.

19 Yadav V, Kumar S, Balasubramaniam S, et al. Facilitators and barriers to participation of private sector health facilities in government-led schemes for maternity services in India: a qualitative study. BMJ Open. 2017;7(6):e017092. Jun 1 .

20 Ganguly P, Jehan K, de Costa A, Mavalankar D, Smith H. Considerations of private sector obstetricians on participation in the state led "Chiranjeevi Yojana" scheme to promote institutional delivery in Gujarat, India: a qualitative study. BMC Pregnancy Childbirth. 2014;14(1):352. Nov 5.

21 Dasgupta R, Nandi S, Kanungo K, Nundy M, Murugan G, Neog R. What the good doctor said: a critical examination of design issues of the RSBY through provider perspectives in Chhattisgarh, India. Soc Change. 2013;43(2):227-243. Jun 1.

22 Irda - Guidelines on Standardization in Health Insurance [Internet]. [cited 2020 Sep 21]. Available from:: http://www.policyholder.gov.in/Guidelines_on_Standardizatio n_in_Health_Insurance.aspx.

23 Altman DG. Practical Statistics for Medical Research. Boca Raton, Fla: Chapman \& Hall/CRC; 1999:611.

24 Kumar Rohit, Rangarajan K, Ranganathan Nagarajan. Health insurance in India-a study of provider's perceptions in Delhi \& the NCR. J Health Manag. 2011;13(3): 259-277. Sep. 1. 